\title{
is Research Square \\ Investigating The Benefits of Online Running Groups On The Well-Being of Their Female Running Members
}

Susan Hughes ( $\nabla$ hughes-s52@ulster.ac.uk)

University of Ulster

Anne Moorhead

University of Ulster

\section{Research Article}

Keywords: women, running, wellbeing, Facebook, social media

Posted Date: August 30th, 2021

DOI: https://doi.org/10.21203/rs.3.rs-800798/v1

License: (a) (1) This work is licensed under a Creative Commons Attribution 4.0 International License. Read Full License 


\section{Abstract}

\section{Background}

Online running communities are becoming increasingly prevalent within social media, and many groups have been exclusively established for female runners. The aim of this study was to investigate the wellbeing benefits and limitations of using Facebook running groups among women.

\section{Methodology}

The research design was a quantitative online survey. This survey was completed by 349 adult members of Facebook running groups for women. The online survey consisted of a validated scale, the Warwick-Edinburgh Mental Wellbeing Scale (WEMWBS), to calculate individual wellbeing scores. Data were analysed using SPSS, conducting descriptives, frequencies and correlations tests.

\section{Results}

The results showed that $14 \%$ of participants' scores indicated a high level of wellbeing, $66 \%$ had a wellbeing score in the moderate range and $21 \%$ of participants scored in the range of low-level wellbeing. Participants specified how they perceived women's running Facebook groups to benefit or limit areas of wellbeing. Responses indicated perceived benefits to sense of optimism, interest in other people and sense of feeling good about themselves. There were negligible perceived wellbeing limitations. Members who had been running for the longest reported to engage more frequently with the groups, which may suggest their identities as runners have strengthened over time.

\section{Conclusion}

Overall, this study clearly found that women's running Facebook groups can provide wellbeing benefits for their members.

\section{Background}

Once considered an elitist sport, running has undergone a change of image in recent years, gaining huge popularity amongst people from all ages, backgrounds and abilities $(9,16)$. According to the Active Lives Survey 2018-2019, 7.1 million adults in England reported they engaged in running at least twice within one month (17). Despite Government restrictions imposed due to the coronavirus pandemic, the same survey reported no significant change in the number of adults engaging in running in 2019-2020, with increased levels of running taking place outdoors as use of treadmills decreased (18).

As social media becomes further integrated into everyday life, it has transformed the ways in which people meet and communicate. Banerjee \& Meena (1) reported social media is used habitually by 3 billion people worldwide as a principal method of connecting with other people and accessing information. They advised dependence on online information has surged as a result of the COVID-19 pandemic and associated isolation, in spite of evidence that a great deal of this material may be incorrect or exaggerated. A hybridisation of sports groups migrating into the online realm is adding a new participatory dimension to sports news and 
information sharing not previously possible with traditional one-way media broadcasting (19). Existing studies have concluded wellbeing can be benefitted by participation in group running such as Parkrun (6) and road races (4). However, there has been a lack of research into the wellbeing benefits or limitations of this transition of sports organisations onto social media platforms.

Research has been conducted into the wellbeing benefits and limitations of social media use in general with mixed results, for example, a systematic review by Erfani \& Abedin (5) found evidence that social network users can experience improved wellbeing in areas such as self-esteem, social supports and sense of belonging. However, the same review found social media sites, predominantly Facebook, can threaten wellbeing and self-esteem, particularly when too much time is invested in their use. A systematic review conducted by Webster, Dunne \& Hunter (21) found adolescents can have either positive or negative experiences of social media. The study found young people could be negatively influenced by 'high investment, passive use and ostracism. Young people reported benefits to their wellbeing as a result of social support on social media, feedback received from peers via social networking sites could be negative or positive depending on the nature of the feedback.

When examining running communities, it is pertinent to consider that many women face increased barriers to sports engagement $(2,3,11)$. Women's opportunities to become runners are reduced due to societal pressures that place expectations on women to carry out the majority of caring and domestic roles within their families (10). Society has been conditioned by generations of patriarchal influences to believe that male bodies are more adept in sport and despite many great female sporting achievements across the world, the media often choose instead to focus on female athletes' behaviour or subject them to sexual objectification (2). Developing relationships with other female runners may help to normalise women's running experiences, rebalance media expectations that women should prioritise family and household tasks, and could strengthen members' identities as female runners (10). A study by Tseng (19) analysed a Facebook fan page for a female Basketball team in Taiwan to examine the potential for such a group to increase media exposure of female athletes and challenge hegemonic masculinity in sport. The study found there was potential for social media coverage of women's sports to break down gender inequality in sports, however, this is most likely when the discourse is led by women or platforms specifically committed to addressing female athlete subordination. The study concluded social media was not universal in this influence, as some accounts continued to utilise language that perpetuated stereotypical and objectifying narratives.

Limited research is available focussing on the wellbeing benefits and limitations of sport communities within a social media context, particularly the pursuit of a causal link between use of these groups and members' sense of wellbeing. Research is required in this area as online sports communities gain popularity, particularly as the Coronavirus pandemic has forced sports authorities to find new ways of engaging with people and sustaining appeal (8). The aim of this study was to investigate the wellbeing benefits and limitations of using Facebook running groups among women. Moreover, this study went further than calculating participant wellbeing scores, by gathering data on how women's running Facebook groups were perceived to benefit or limit areas of wellbeing.

This study tested two hypotheses: 
Null Hypothesis 1: There is no significant relationship between total wellbeing score and reading posts within women's running Facebook groups

Null Hypothesis 2: There is no significant relationship between total wellbeing score and contributing to posts within women's running Facebook groups

\section{Methods}

\section{Research design}

Whilst debate exists in relation to the suitability of quantitative research methods in the study of people and social sciences, literature indicates when used with large groups of people, quantitative methods can successfully be utilised to test hypotheses about human behaviour (15). Quantitative methodology was employed in this study. Data were collected via an online survey, the benefits of this approach including being less time consuming than interviews, providing a standardised experience for all participants and eliminating the possibility of the researcher influencing responses (12). The online nature of the survey was considered suitable for this study as the objective is to understand online behaviours, particularly in relation to wellbeing benefits and limitations of using Facebook running groups among women. Ethical approval was granted for this study by the School of Communication \& Media Filter (Ethics) Committee, Ulster University.

\section{Participants \& Recruitment}

Participants were female adult runners who met the eligibility inclusion criteria if they were female, over 18 years old and were members of at least one women's running Facebook group. Exclusion criterion was the absence of consent to take part. Convenience sampling of 349 female runners participated in this online survey. Participants were recruited by sharing a link on Facebook running group pages, which included participant information, consent form and the URL to the online survey.

\section{Data collection Tool - online questionnaire}

The purpose of the online questionnaire was to investigate the wellbeing benefits and limitations of using Facebook running groups among women. The questionnaire consisted of the following sections: demographics, running habits, use of Facebook running groups, the Warwick-Edinburgh Mental Wellbeing Scale (20), impact of wellbeing, and an opportunity to provide other relevant comments. The WEMWBS (20) is a validated measure of personal wellbeing, posing 14 statements each with 5-point Linkert scale answers. The sum of the responses provides a wellbeing score for each respondent, a score totalling less than 43 is indicative of a low level of wellbeing, scores between 43-61 indicate a moderate level of wellbeing and a score over 61 is considered to represent a high level of wellbeing (20). The WEMWBS was used in the study questionnaire to measure the wellbeing of each participant. A license was approved from WEMWBS to do this. The women were also asked if they perceive women's running Facebook groups to benefit or limit each area of wellbeing as included on the WEMWBS.

\section{Data collection procedures}


Participants were provided with information about the study including link to the survey via numerous Facebook groups for female runners in the UK. Once the participants provided consent, they were asked to complete an online questionnaire. The online survey was hosted on the online survey platform, JISC. Participants competed the online survey at a time and place of their own convenience. The survey was approximately 10 minutes duration. Data collection took place in February 2020.

\section{Data analysis}

Data from completed questionnaires were directly imported into Statistical Package for the Social Sciences (SPSS) Version 26. Descriptives and frequencies were conducted to determine the patterns in the variables. Spearman's Correlations were performed to establish if there were any significant relationships between participant demographics, usage of groups, wellbeing scores and perceived of impact of groups on wellbeing. The level of significance was $\mathrm{P}<0.05$.

\section{Results}

In total, 349 participants, women's running Facebook groups members, completed the online survey. The majority of the women were aged 36-55 years, with 36\% aged between 36-45 years and 34\% aged 46-55 years. Almost half of participants (45\%) had achieved degree level of education, $20 \%$ finished their education at primary or secondary school level, $20 \%$ had attained a Masters level qualification and $5 \%$ of participants had achieved education at a doctorate level. The $12 \%$ of participants who selected the 'other' category had achieved unspecified levels of education including diploma, NVQ and post-graduate qualifications.

\section{Uses of women's running Facebook groups}

The reported key uses of women's running Facebook groups were access to training advice and support (79\%), motivation to run (72\%) and being part of a community (71\%). A significant positive relationship was found to exist between the length of time as a runner and length of membership to the groups (Spearman's correlation coefficient $=0.325, P=0.000$ ). The length of time as a runner was also significantly positively correlated with the frequency of reading posts on women's running Facebook groups (Spearman's correlation coefficient $=$ $0.115, P=0.032)$.

The highest reported frequency of reading posts on women's running Facebook groups was several times a day, as reported by $58 \%$ participants. Only $14 \%$ of the 349 participants responded they read posts less than once a day. However, frequency of contributing to posts within the groups was lower, as $32 \%$ of participants indicated they contributed to posts less than once a month. From the 349 participants, $7 \%$ advised they contributed several times a day and $12 \%$ contributed to posts once a day. This demonstrates users of women's running Facebook groups read posts much more frequently than they contribute to them, which suggests the group members prefer to learn about other's experiences than share their own.

\section{Wellbeing scores among members of women's running Facebook groups}


The mean wellbeing score for participants was in the moderate range $(M=50.8, S D=10.2)$. The minimum score achieved by a study participant was 14 and the maximum score was 70. Analysis of the WEMWBS revealed that $14 \%$ of participants had a high level of wellbeing, $66 \%$ had a moderate level of wellbeing, and $21 \%$ scored in the low range of wellbeing, as shown in Fig. 1. The lowest scored statement was "I have had energy to spare' $(M=3.19, S D=0.99)$ and the highest scored statement was "I've been able to make my mind up about things' $(\mathrm{M}=3.90, \mathrm{SD}=0.90)$ as shown in Table 1. 
Table 1

Warwick-Edinburgh Mental Wellbeing Scale Scores $(n=349)$

\begin{tabular}{|c|c|c|c|c|c|c|c|c|c|c|c|c|c|}
\hline \multirow[t]{2}{*}{ Statement } & \multicolumn{3}{|c|}{$\begin{array}{l}\text { 1. None of the } \\
\text { time }\end{array}$} & \multicolumn{2}{|c|}{ 2.Rarely } & \multicolumn{2}{|c|}{$\begin{array}{l}\text { 3.Some of } \\
\text { the time }\end{array}$} & \multicolumn{2}{|c|}{ 4.0ften } & \multicolumn{2}{|c|}{$\begin{array}{l}\text { 5.All of the } \\
\text { time }\end{array}$} & \multirow[t]{2}{*}{ Mean } & \multirow[t]{2}{*}{ SD } \\
\hline & No. & $\%$ & & No. & $\%$ & No. & $\%$ & No. & $\%$ & No. & $\%$ & & \\
\hline $\begin{array}{l}\text { l've been } \\
\text { feeling } \\
\text { optimistic } \\
\text { about the } \\
\text { future }\end{array}$ & 6 & 1.7 & & 18 & 5.2 & 91 & 26.1 & 183 & 52.4 & 51 & 14.6 & 3.73 & 0.84 \\
\hline $\begin{array}{l}\text { I've been } \\
\text { feeling } \\
\text { useful }\end{array}$ & 7 & 23 & 6.6 & 88 & 25.2 & 170 & 48.7 & 61 & 17.5 & 3.73 & 0.89 & & \\
\hline $\begin{array}{l}\text { I've been } \\
\text { feeling } \\
\text { relaxed }\end{array}$ & 5 & 1.4 & & 57 & 16.3 & 134 & 38.4 & 126 & 36.1 & 27 & 7.7 & 3.32 & 0.89 \\
\hline $\begin{array}{l}\text { l've been } \\
\text { feeling } \\
\text { interested } \\
\text { in other } \\
\text { people }\end{array}$ & 5 & 1.4 & & 18 & 5.2 & 89 & 25.5 & 170 & 48.7 & 67 & 19.2 & 3.79 & 0.86 \\
\hline $\begin{array}{l}\text { I've had } \\
\text { energy to } \\
\text { spare }\end{array}$ & 11 & 3.2 & & 75 & 21.5 & 135 & 38.7 & 92 & 26.4 & 36 & 10.3 & 3.19 & 0.99 \\
\hline $\begin{array}{l}\text { l've been } \\
\text { dealing } \\
\text { with } \\
\text { problems } \\
\text { well }\end{array}$ & 9 & 2.6 & & 25 & 7.2 & 113 & 32.4 & 163 & 46.7 & 39 & 11.2 & 3.57 & 0.88 \\
\hline $\begin{array}{l}\text { I've been } \\
\text { thinking } \\
\text { clearly }\end{array}$ & 5 & 1.4 & & 18 & 5.2 & 100 & 28.7 & 170 & 48.7 & 56 & 16 & 3.73 & 0.84 \\
\hline $\begin{array}{l}\text { I've been } \\
\text { feeling } \\
\text { good } \\
\text { about } \\
\text { myself }\end{array}$ & 9 & 2.6 & & 37 & 10.3 & 108 & 30.9 & 147 & 42.1 & 48 & 13.8 & 3.54 & 0.94 \\
\hline $\begin{array}{l}\text { I've been } \\
\text { feeling } \\
\text { close to } \\
\text { other } \\
\text { people }\end{array}$ & 6 & 1.7 & & 35 & 10 & 104 & 29.8 & 155 & 43.3 & 53 & 15.2 & 3.60 & 0.92 \\
\hline $\begin{array}{l}\text { I've been } \\
\text { feeling } \\
\text { confident }\end{array}$ & 11 & 3.2 & & 45 & 12.9 & 117 & 33.5 & 138 & 39.5 & 38 & 10.9 & 3.42 & 0.95 \\
\hline
\end{tabular}




\begin{tabular}{|c|c|c|c|c|c|c|c|c|c|c|c|c|c|}
\hline \multirow[t]{2}{*}{ Statement } & \multicolumn{3}{|c|}{$\begin{array}{l}\text { 1. None of the } \\
\text { time }\end{array}$} & \multicolumn{2}{|c|}{ 2.Rarely } & \multicolumn{2}{|c|}{$\begin{array}{l}\text { 3.Some of } \\
\text { the time }\end{array}$} & \multicolumn{2}{|c|}{ 4.0ften } & \multicolumn{2}{|c|}{$\begin{array}{l}\text { 5.All of the } \\
\text { time }\end{array}$} & \multirow[t]{2}{*}{ Mean } & \multirow[t]{2}{*}{ SD } \\
\hline & No. & $\%$ & & No. & $\%$ & No. & $\%$ & No. & $\%$ & No. & $\%$ & & \\
\hline $\begin{array}{l}\text { I've been } \\
\text { able to } \\
\text { make up } \\
\text { my own } \\
\text { mind } \\
\text { about } \\
\text { things }\end{array}$ & 5 & 1.4 & & 24 & 6.9 & 59 & 16.9 & 175 & 50.1 & 86 & 24.6 & 3.90 & 0.90 \\
\hline $\begin{array}{l}\text { I've been } \\
\text { feeling } \\
\text { loved }\end{array}$ & 9 & 2.6 & & 21 & 6 & 73 & 20.9 & 147 & 42.1 & 99 & 28.4 & 3.88 & 0.98 \\
\hline $\begin{array}{l}\text { I've been } \\
\text { interested } \\
\text { in new } \\
\text { things }\end{array}$ & 6 & 1.7 & & 25 & 7.2 & 89 & 25.5 & 153 & 43.8 & 76 & 21.8 & 3.77 & 0.93 \\
\hline $\begin{array}{l}\text { l've been } \\
\text { feeling } \\
\text { cheerful }\end{array}$ & 7 & 2 & & 24 & 6.9 & 107 & 30.7 & 164 & 47 & 47 & 13.5 & 3.63 & 0.87 \\
\hline \multirow{3}{*}{$\begin{array}{l}\text { Total } \\
\text { overall } \\
\text { scores }\end{array}$} & \multicolumn{2}{|l|}{ Mean } & \multicolumn{3}{|c|}{50.80} & & & & & & & & \\
\hline & \multicolumn{2}{|l|}{ SD } & \multicolumn{3}{|c|}{10.20} & & & & & & & & \\
\hline & \multicolumn{2}{|c|}{ Range } & 56 & & & & & & & & & & \\
\hline
\end{tabular}

Participants aged 56-65 years had the highest wellbeing scores $(M=53.8)$ and those over 65 years old scored the lowest $(M=49.0)$. A general trend was apparent when the wellbeing scores were arranged according to participants' highest level of education. As the level of education increased, so did the total wellbeing score with the exception of those who finished their education at primary school level. Participants who finished their education at primary school presented an anomaly with an average wellbeing score of 52.0, this was the second highest scoring category of education.

\section{Perceived wellbeing benefits of women's running Facebook groups}

From the 349 participants, $15 \%$ reported that the Facebook running groups benefitted their wellbeing all the time, $47 \%$ reported the groups benefitted their wellbeing often and $33 \%$ indicated the groups benefitted their wellbeing some of the time. A minority of participants (4\%) reported the groups rarely benefitted their sense of wellbeing and 1\% responded "I don't know'. When asked how women's running Facebook groups affected areas of wellbeing (Table 2), 70\% of participants reported women's running Facebook groups had benefitted their sense of optimism, $73 \%$ stated that the groups benefitted their sense of interest in other people, $68 \%$ indicated the groups improved their sense of feeling good about themselves and $61 \%$ reported the groups benefitted their interest in new things. 
Table 2

\begin{tabular}{|c|c|c|c|c|c|c|c|c|}
\hline \multirow[t]{2}{*}{ Statement } & \multicolumn{2}{|c|}{ Positively } & \multicolumn{2}{|c|}{ No Change } & \multicolumn{2}{|c|}{ Negatively } & \multicolumn{2}{|c|}{ Don't know } \\
\hline & No. & $\%$ & No. & $\%$ & No. & $\%$ & No. & $\%$ \\
\hline Sense of optimism & 245 & 70.2 & 93 & 26.6 & 5 & 1.4 & 6 & 1.7 \\
\hline Sense of feeling useful & 142 & 40.7 & 199 & 57 & 2 & 0.6 & 6 & 1.7 \\
\hline Sense of feeling relaxed & 121 & 34.7 & 216 & 61.9 & 3 & 0.9 & 9 & 2.6 \\
\hline Interest in other people & 255 & 73.1 & 86 & 24.6 & 3 & 0.9 & 5 & 1.4 \\
\hline Energy levels & 147 & 42.1 & 192 & 55 & 2 & 0.6 & 8 & 2.3 \\
\hline Ability to deal with problems & 118 & 33.8 & 222 & 63.6 & 0.3 & 8 & 2.3 & \\
\hline Ability to think clearly & 99 & 28.4 & 241 & 69.1 & 2 & 0.6 & 7 & 2 \\
\hline Sense of feeling good about myself & 236 & 67.6 & 101 & 28.9 & 8 & 2.3 & 4 & 1.1 \\
\hline Sense of feeling close to other people & 199 & 57 & 137 & 39.3 & 7 & 2 & 6 & 1.7 \\
\hline Confidence levels & 199 & 57 & 134 & 38.4 & 9 & 2.6 & 7 & 2 \\
\hline Ability to make my mind up about things & 91 & 26.1 & 248 & 71.1 & 2 & 0.6 & 8 & 2.3 \\
\hline Sense of feeling loved & 92 & 26.4 & 247 & 70.8 & 3 & 0.9 & 7 & 2 \\
\hline Levels of interest in new things & 211 & 60.5 & 126 & 36.1 & 5 & 1.4 & 7 & 2 \\
\hline Sense of feeling cheerful & 190 & 54.4 & 152 & 43.6 & 2 & 0.6 & 5 & 1.4 \\
\hline
\end{tabular}

Participants did not perceive the groups to benefit all areas of wellbeing, with $71 \%$ advising the groups had no influence on their ability to make their mind up about things and $71 \%$ reported the groups did not change their sense of feeling loved. A minority of participants indicated a perception of wellbeing limitation, $3 \%(N=9)$ of participants reported the groups negatively influenced their confidence levels, and $2 \%(\mathrm{~N}=7)$ reported women's running Facebook groups decreased their sense of feeling close to other people.

Two hypotheses were tested:

Null Hypothesis 1: There is no significant relationship between total wellbeing score and reading posts within women's running Facebook groups

Null Hypothesis 2: There is no significant relationship between total wellbeing score and contributing to posts within women's running Facebook groups

Spearman's correlations found a significant negative correlation between participant age and frequency of reading posts and contributing to posts on the group (correlation co-efficient $=-0.151 \&-0.192, p=0.005 \&$ 0.000 respectively), indicating that older women read and contribute to significantly fewer Facebook running 
posts. A significant negative relationship was also found between overall wellbeing score and frequency of reading posts and contributing to posts on the groups (correlation coefficient $=0.131 \& 0.126, p=0.014$ \& 0.018 respectively), thus indicating that overall wellbeing scores significantly decreased as the frequency of reading and contributing to Facebook running posts increased. This could indicate women's running Facebook groups have a limiting effect on overall wellbeing, or alternatively it may suggest that female runners with lower wellbeing are more likely to read and contribute to posts within the groups. The outcome of the study was the two null hypotheses could be rejected as follows:

Null Hypothesis 1: There is no significant relationship between total wellbeing score and reading posts within women's running Facebook groups - Rejected (correlation co-efficient $=-0.131, \mathrm{P}=0.014$ ).

Null Hypothesis 2: There is no significant relationship between total wellbeing score and contributing to posts within women's running Facebook groups - Rejected (correlation co-efficient $=-0.126, \mathrm{P}=0.018$ ).

The participants' WEMWBS responses (Table 1) were compared with the perceived benefits and limitations of women's running Facebook groups (Table 2) in a further Spearmans correlations. A significant relationship was found universally between the corresponding statements. This result was key in answering the posed research question, as the evidence suggests women's running Facebook groups have the potential to benefit members' wellbeing. The main finding of this survey was that members of women's running Facebook groups reported wellbeing benefits of using the online running groups.

\section{Discussion}

This study aimed to investigate the wellbeing benefits and limitations of women's running Facebook groups. The results clearly showed that participants perceive Facebook running groups to benefit areas of their wellbeing, with negligible indication of perceived wellbeing limitations. Participants perceived the groups to benefit their sense of optimism, interest in others, interest in new things, and a sense of feeling good about themselves. The responses indicated the groups are not perceived to influence feelings of relaxation, energy levels, sense of feeling useful, ability to deal with problems, the participants' ability to make their minds up about things, their ability to think clearly and their sense of feeling loved. The generally positive perception of the groups' wellbeing benefits supports findings by Erfani \& Abedin (5) that social media users reported benefits to feelings of belonging, social support and confidence.

Whilst the majority (85\%) of participants visit women's running Facebook groups to read posts on a daily basis, only $20 \%$ contribute to posts every day. The data would suggest that many participants still perceive wellbeing benefits from the groups, even when opting not to share their own experiences. This may be due in part to the normalising and motivating effect of reading about women's sporting experiences, challenging the patriarchal attitudes and barriers to sport experienced by many women as found by McGannon, McMahon \& Gonsalves (10). This is an important finding as social media group moderators can benefit from knowing the habits of their members. This result suggests the influence of social media posts is much wider than it appears, as many users choose to remain 'silent' within the groups they frequent. This finding also establishes for future studies that it is not possible to fully assess the wellbeing benefits or limitations of social media communities by merely observing the activities within the group, as much of the members' engagement is invisible to an outsider.

Page 10/15 
Participants who had been running for the longest reported they had been members of the groups for longer and spent more time reading posts on the groups. This may be attributed to the assimilation of running into an individual's identity over time, as found by Robinson et al. (14), which can lead to a decreased reliance on nonrunning peer groups and the drive to connect instead with other runners.

A significant negative relationship between participants' age and frequency of reading and contributing to group posts suggests that young members are significantly more likely to engage more frequently with women's running Facebook groups. This finding supports Perrin (13) who found that 18-29 year olds use social media more than other age groups. Hardy \& Castonguay (7) found the use of social media offered wellbeing benefits for young adults, but posed threats to the wellbeing of middle-aged and older adults. They speculated this may be due to an increased propensity for adults over the age of 30 years to engage in social comparison, an element of online communities that can compromise sense of wellbeing.

A significant negative correlation between wellbeing score and frequency of reading and contributing to posts may be suggestive that too much time engaged with women's running Facebook groups could pose wellbeing limitations. Alternatively, as the majority of participants did not perceive the groups to reduce their overall wellbeing, this finding is suggestive that a lower wellbeing score may result in increased engagement with the groups.

\section{Implications for practice}

This research has found that women's running Facebook groups have the potential to benefit members' wellbeing, even when those members are not contributing to posts. This provides a useful insight into the habits of group users. The finding suggests that group moderators should be mindful of conversations that take place within their communities, as they are likely to influence their most active contributors as well as 'silent' members.

This research also suggests that excessive use of women's running Facebook groups may contribute to a reduced sense of wellbeing. With this in mind, it would be pertinent for social media users and moderators to raise community awareness regarding this and promote a balanced approach to online interaction.

\section{Limitations}

This online survey has a few limitations. These include the relatively small sample size of 349 Facebook running group women members. A larger sample size could have benefitted the study by providing more generalisations. The participants of this study were UK members and this survey could have included international members, thus providing a global perspective. Finally, a baseline reading of participant wellbeing was not available, so it is not possible to know if there was a change in overall wellbeing score since the participants joined a women's running Facebook group.

\section{Further research}


This research could be developed further with implementation of a longitudinal design by asking participants to repeat the questionnaire at set time-points. This would aid investigation into the ways in which fluctuations in wellbeing might influence social media behaviours, including changes through the COVID-19 pandemic, lockdowns and easing of restrictions. The research also has scope to be extended across various social media platforms for further comparison.

\section{Conclusion}

This study found a link may exist between overall wellbeing and the use of women's running Facebook groups. The results suggest women with lower wellbeing may be more likely to read group posts and contribute to the posts more frequently. This study made a valuable contribution as it was the first to calculate participants' overall wellbeing scores as well as the perceived wellbeing benefits and limitations of women's running Facebook groups. The results showed the perceived wellbeing benefits reported by participants correlated with their responses to the WEBWMS. The data collection tool used has the capacity to be repeated infinitely and the research could be developed for greater validity by gathering further data samples, or by asking the same individuals to complete the questionnaire multiple times in a longevity study. Overall, the results of this study suggest women's running Facebook groups can offer wellbeing benefits for female runners.

\section{Declarations}

\section{Ethics approval and consent to participate}

As this research involved human participants, ethical approval was sought prior to data collection. The study was Category A low risk research, conducting a survey with healthy adult volunteers. Ethical approval for all research protocols was granted for this study by the School of Communication \& Media Filter (Ethics) Committee, Ulster University. All participants were over the age of 18 and informed consent was obtained from all subjects prior to taking part in the study. All methods were carried out in accordance with the Ulster University Code of Practice for Professional Integrity in the Conduct of Research and relevant legislation.

\section{Consent for publication}

Not applicable as no personal identifiable information was collected as part of this study.

\section{Availability of data and materials}

The datasets used and/or analysed during the current study are available from the corresponding author on reasonable request.

\section{Competing interests}

The authors declared no competing interests with respect to the research, authorship, and/or publication of this article.

\section{Funding}


This project was part of MSc, funded by the Southern Health and Social Care Trust. The corresponding author was employed by Southern Health and Social Care Trust at the time of the study, and they covered all tuition fees for the MSc as part of a commitment to continued professional development. The Southern Health and Social Care Trust were not involved in choosing the research topic.

\section{Authors' contributions}

SH designed the online questionnaire, recruited participants and collected the data. AM supported and supervised $\mathrm{SH}$ throughout this process. AM assisted with analysis and interpretation of the data. SH drafted the manuscript and AM substantively revised it. All authors read and approved the final manuscript. Both authors have agreed both to be personally accountable for their own contributions and to ensure that questions related to the accuracy or integrity of any part of the work, even ones in which the author was not personally involved, are appropriately investigated, resolved, and the resolution documented in the literature.

\section{Acknowledgements}

Not applicable.

\section{Authors' information}

Dr Anne Moorhead is a Lecturer in Health Communication at Ulster University. She has a MA Psychology, MSc Nutrition and Dietetics, and PhD Biomedical Sciences (Nutrition); and is a Registered Nutritionist, Public Health (RNutr), Chartered Scientist (CSci), and Accredited Healthcare Communicator.

Susan Hughes is a PhD researcher at Ulster University. She completed an MSc in Counselling Studies and Health Communication in September 2020.

\section{References}

1. Banerjee D, Meena KS. (2021). COVID-19 as an "Infodemic" in Public Health: Critical Role of the Social Media. Frontiers in Public Health. 2021; doi:10.3389/fpubh.2021.610623.

2. Choi PYL. Femininity and the physically active woman. London: Routledge; 2000.

3. Cramp AG, Brawley LR. Moms in motion: a group-mediated cognitive-behavioural physical activity intervention. International Journal of Behavioural Nutrition and Physical Activity, 2006; doi:10.1186/14795868-3-23.

4. Cypryańska M, Nezlek JB. Everyone can be a winner: The benefits of competing in organized races for recreational runners. The journal of positive psychology. 2018; doi:10.1080/17439760.2018.1557244.

5. Erfani SS, Abedin B. Impacts of the Use of Social Network Sites on Users' Psychological Well-being: A Systematic Review. Journal of the association for information science and technology. 2018; doi:10.1002/asi.24015.

6. Grunseit A, Richards J, Merom D. Running on a high: parkrun and personal well-being. BMC Public Health. 2017; doi:10.1186/s12889-017-4620-1. 
7. Hardy BW, Castonguay J. The moderating role of age in the relationship between social media use and mental well-being: An analysis of the 2016 General Social Survey. Computers and Human Behaviour, 2018; doi:10.1016/j.chb.2018.04.005.

8. Hayes M. Social media and inspiring physical activity during COVID-19 and beyond. Managing Sport and Leisure. 2020; doi:10.1080/23750472.2020.1794939.

9. Hindley D. "More than just a run in the park": An exploration of parkrun as a shared leisure space. Leisure Sciences. 2020; doi:10.1080/01490400.2017.1410741.

10. McGannon KR, McMahon J, Gonsalves, CA. Mother runners in the blogsphere: A discursive psychological analysis of online recreational athlete identities. Psychology of Sport and Exercise. 2017.

doi:10.1016/j.psychsport.2016.11.002.

11. Moreno JP, Johnston CA. Barriers to Physical Activity in Women. American Journal of Lifestyle Medicine. 2014 doi:10.1177/1559827614521954.

12. Nardi P. Doing Survey Research: A Guide to Quantitative Methods. 4th edn. Routledge: New York; 2018

13. Perrin A. Social Networking Usage: 2005-2015. Pew Research Center. 2015. https://www.pewresearch.org/internet/wp-content/uploads/sites/9/2015/10/PI_2015-10-08_SocialNetworking-Usage-2005-2015_FINAL.pdf. Accessed 21 June 2021.

14. Robinson R, Patterson I, Axelsen M. The “Loneliness of the Long-Distance Runner" No More. Journal of Leisure Research. 2014; doi:10.1080/00222216.2014.11950333.

15. Rolfe G. Philosophical Basis for Research. In: Curtis EA, Drennan J. Quantitative Health Research - Issues and Methods, Open University Press: Maidenhead; 2013. p. 11-28.

16. Shipway R, Holloway I. Running free: Embracing a healthy lifestyle through distance running. Perspectives in Public Health. 2010; doi:10.1177/1757913910379191.

17. Sport England. Active Lives Adult Survey: May 18/19 Report, UK Data Service, SN: 8652. 2019, https://sportengland-production-files.s3.eu-west-2.amazonaws.com/s3fs-public/active-lives-adult-may-1819-report.pdf. Accessed 21 June 2021.

18. Sport England. Active Lives Adult Survey: Mid-March to mid-May 19/20 Report, Coronavirus (Covid-19) Report, UK Data Service, SN: 8652. 2020, https://sportengland-production-files.s3.eu-west-

2.amazonaws.com/s3fs-public/2020-10/Active\%20Lives\%20Adult\%20May\%201920\%20Coronavirus\%20Report.pdf?2L6TBVV5UvCGXb_VxZcWHcfFX0_wRal7. Accessed 21 June 2021.

19. Tseng YH. Representing sporting female discourse in social media - Taiwan women's basketball Facebook page ‘Double Pump' as an example. Sport in Society. 2020; doi:10.1080/17430437.2020.1763959.

20. Warwick Medical School. The Warwick-Edinburgh Mental Wellbeing Scale (WEMWBS). 2020, https://warwick.ac.uk/fac/sci/med/research/platform/wemwbs. Accessed 13 January 2020.

21. Webster D, Dunne L, Hunter R. Association between social networks and subjective well-being in adolescents: A systematic review'. Youth \& Society. 2021; doi:10.1177/0044118X20919589.

\section{Figures}




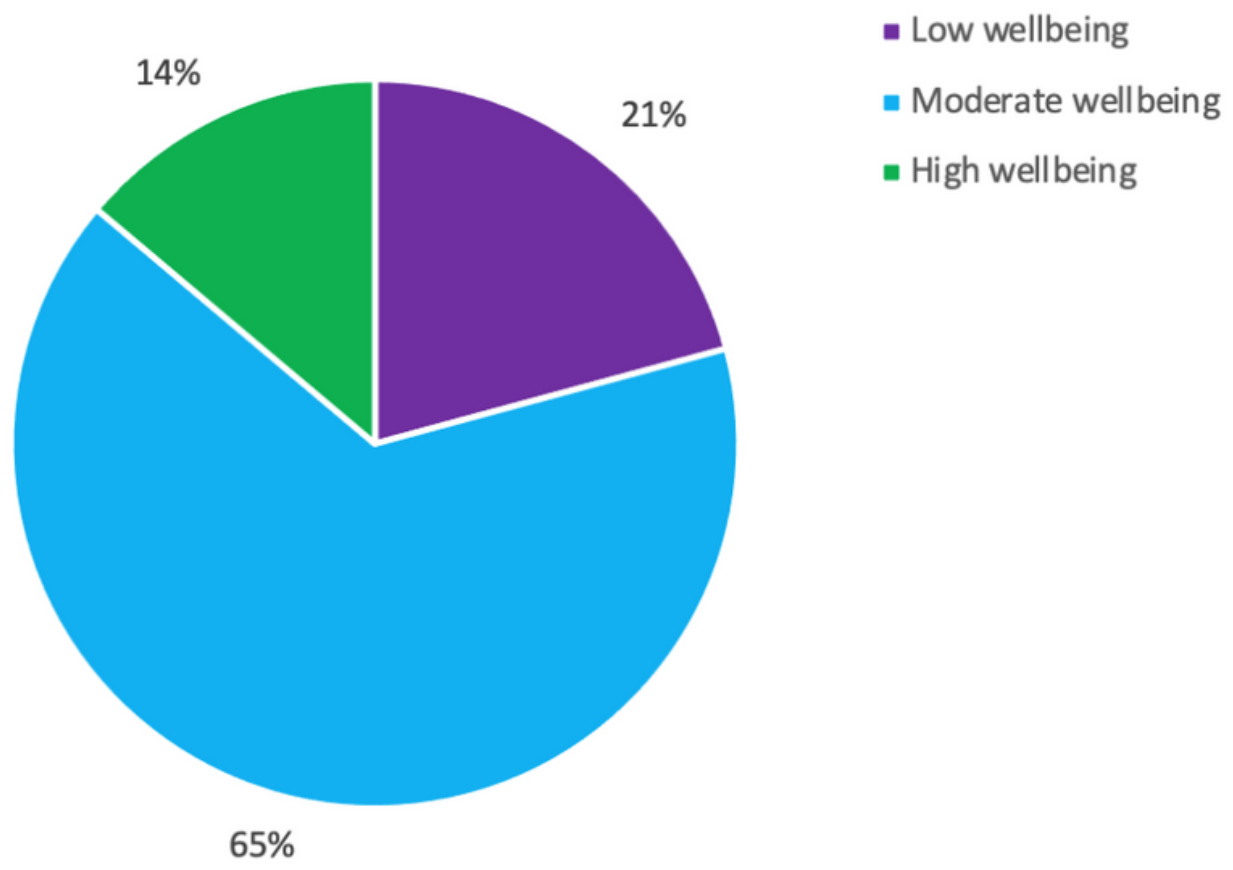

\section{Figure 1}

The level of wellbeing as calculated by Warwick-Edinburgh Mental Wellbeing Scale $(n=349)$ 